\title{
Regional climate modeling for Asia
}

\author{
Dong-Kyou Lee ${ }^{1}$ and Dong-Hyun Cha ${ }^{2^{*}}$ (D)
}

\begin{abstract}
The regional climate model (RCM) with higher resolution and sophisticated physical processes can reproduce and project fine-scale climate information, which cannot be captured by the global climate model (GCM). Therefore, we developed the Seoul National University Regional Climate Model (SNURCM) in the 1990s to simulate the intrinsic and detailed climate prevailing in Asia. In this study, we reviewed the developmental processes of the SNURCM and its application researches. In the simulation of regional climate over Asia, systematic errors can be generated because of natural characteristics such as complex land-surface conditions and topography, warm ocean conditions, and strong seasonal monsoon circulation and convection. Numerous methods and techniques have been applied to reduce these errors and improve the SNURCM. For long-term simulations without climate drift, the spectral nudging technique as well as the traditional relaxation method was employed for the boundary conditions. To represent reasonable interactions between earth systems, a simple ocean model and an advanced land-surface model were implemented into the SNURCM. Physical schemes for precipitation and vertical diffusion developed for short-term numerical weather prediction models were optimized or improved for long-term simulation. The SNURCM has been applied to future climate projection, reproduction of extreme climate, and seasonal forecasting. Furthermore, the model has served as a part of the multi-model comparison program and an ensemble of international research programs.
\end{abstract}

Keywords: Regional climate modeling, Asia, Climate change, International collaboration

\section{Introduction}

Accurate and detailed climate information is needed for the efficient management of natural disasters related to high-impact weather and climate events, which have become more frequent and extreme. Asia has an intricate coastline and topography, and multiscale atmospheric phenomena occur over it (Wang et al. 2004; Lee et al. 2004). In addition, Asia is significantly vulnerable to natural disasters due to the increasing number of climate extremes under the changing climate and the societal impacts caused by a large population (Stocker et al. 2014). Therefore, it is natural that researchers have focused on the prediction of regional climate change over Asia.

\footnotetext{
*Correspondence: dhcha@unist.ac.kr

${ }^{2}$ School of Urban and Environmental Engineering, Ulsan National Institute of Science and Technology (UNIST), 50 UNIST-gil, Ulju-gun, Ulsan 689-798, Republic of Korea

Full list of author information is available at the end of the article
}

Regional climate modeling is a dynamical downscaling method that embeds regional features within coarse-resolution global climate models (GCMs), which have the ability to predict large-scale variability (Dickinson et al. 1989; Giorgi 1990). Downscaling enhances or adds value to regional information provided by coupled GCMs (Giorgi 2006). GCMs have been commonly employed to estimate large-scale climate information. Nevertheless, it is difficult for GCMs to represent the effectiveness of local-to-regional-scale forcings such as complex topography and land-surface characteristics owing to limitations of low-resolution climate information. Regional climate modeling started since the late 1980 s as a dynamical downscaling method. RCMs can resolve smaller-scale atmospheric features embedded within the large-scale forcings and hence were developed and applied to provide detailed climate information (Giorgi and Mearns 1999; Wang et al. 2004; Prudhomme et al. 2012; Mezghani et al. 2017).
Springer Open

(c) The Author(s) 2020. This article is licensed under a Creative Commons Attribution 4.0 International License, which permits use, sharing, adaptation, distribution and reproduction in any medium or format, as long as you give appropriate credit to the original author(s) and the source, provide a link to the Creative Commons licence, and indicate if changes were made. The images or other third party material in this article are included in the article's Creative Commons licence, unless indicated otherwise in a credit line to the material. If material is not included in the article's Creative Commons licence and your intended use is not permitted by statutory regulation or exceeds the permitted use, you will need to obtain permission directly from the copyright holder. To view a copy of this licence, visit http://creativeco mmons.org/licenses/by/4.0/. 
First, RCMs are widely used for the projection of future regional climate scenarios (Giorgi et al. 1994; Leung and Ghan 1999, Lee et al. 2013; Kim et al. 2020a) and the assessment of impacts of climate change on agriculture, hydrological cycles, and typhoons (Kim et al. 2000; Xue et al. 2001; Ahn and Lee 2002; Jeon et al. 2019). In addition, RCMs can be powerful tools for the prediction or simulation of Asian climate, including anomalous climate events such as droughts and floods because they have the ability to capture weather phenomena at various spatial and temporal scales. Many studies have indicated that when driven by large-scale conditions such as global reanalysis data, RCMs can properly reproduce regional-scale features such as extreme climate events (Giorgi and Shields 1999; Sun et al. 1999; Lee and Suh 2000; Wang et al. 2003; Lee et al. 2004), diurnal variation of precipitation (Dai et al. 1999; Zhang et al. 2003a, b), orographic precipitation (Leung and Ghan 1998; Kim et al. 2000), and regional climate anomalies related to the ENSO (Leung et al. 2003). The RCM approach is also employed to understand climate processes associated with land-surface processes, cumulus convection, and cloud radiative forcing (e.g., Schär et al. 1999; Bosilovich and Sun 1999; Cha et al. 2011a; Yoon et al. 2018; Kim et al. 2019).s

In the late 1990s, we developed the Seoul National University Regional Climate Model (SNURCM) to simulate the intrinsic and detailed climate in Asia. The SNURCM has been one of the representative RCMs for East Asian climate used for a number of regional climate modeling studies and application researches. In this study, we review the prospects of developing the SNURCM ("Development of RCMs" section) and introduce its various applications and international cooperation ("Application and international cooperation" section) to provide helpful information to RCM developmental studies and application researches. Suggestions for further development of RCMs are also provided in "Conclusion" section.

\section{Development of RCMs}

In the late 1990s, the SNURCM was developed based on the Penn State University/National Center for Atmospheric Research (PSU/NCAR) mesoscale model version 5 (MM5) (Grell 1994), which is a non-hydrostatic limitedarea model with terrain-following sigma-coordinates designed to predict mesoscale atmospheric features. The SNURCM comprises three models for atmosphere, land surface, and ocean. These models are the MM5, NCAR community land-surface model (CLM) (Bonan et al. 2002), and slab ocean model (SOM) (Zeng et al. 2002). In this section, we introduce the development process of the SNURCM.

\section{a) Coupling with sophisticated land-surface models}

Land-surface process can affect East Asian monsoon in a very complex way because the interaction between the atmosphere and land surface is involved with the complicated coupling of hydrologic and energy cycles. Kim and Hong (2007) showed that there can be positive feedback as well as negative one between soil moisture and monsoon precipitation in Asia, which may lead to a weak impact of soil moisture anomalies on summer precipitation due to a conflict between different feedback processes. Therefore, physical interaction between land surface and atmosphere is essential for the simulation of climatic features.

In the MM5, there are several land-surface models (LSMs) available for simulating the land-air interaction process such as 5-layer soil model, the Noah LSM, and the Pleim-Xiu LSM. However, the 5-layer soil model was designed for short-term weather forecast, and the PleimXiu LSM could not be available because of the limitation of the planetary boundary scheme. Therefore, first, a comprehensive and advanced land-surface parameterization scheme, the NCAR land-surface model (NCAR LSM) (Bonan 1996), was coupled with the MM5 for the land-surface and soil physical processes (Kang et al. 2005; Zhang et al. 2009). Kang et al. (2005) showed that the SNURCM with the NCAR LSM could improve the simulation of the East Asian summer monsoon compared with that with the simple 5-layer soil model because the NCAR LSM more reasonably simulated the land-air interaction process. The NCAR LSM was replaced with the NCAR community land model (CLM). The coupled CLM plays an essential role in improving land-surface processes in the SNURCM. The notable advantages of the coupling of CLM are that complex land-surface types in Asia can be represented by the plant function type (PFT) and that the physical feedback process between soil moisture and monsoon precipitation can be more reasonably simulated due to more soil layers and improved parameterization.

\section{b) Implementation of spectral nudging technique}

Most RCMs are based on high-resolution limited-area models, which require lateral boundary conditions. This indicates that large-scale atmospheric conditions such as GCM output or global reanalysis data must be provided to a RCM and that spurious interactions between the lateral boundaries and the model solution must be avoided (Marbaix et al. 2003). To avoid such spurious interactions, most RCMs have employed the relaxation method suggested by Davies and Turner (1977) as the lateral boundary condition. However, von Storch et al. (2000) proposed the spectral nudging technique (SNT) as 
an alternate method. Forcing in spectral nudging is stipulated at the model's interior as well as lateral boundaries. The SNT is not only to keep the large-scale regime of RCM's solution similar to large-scale driving forces, but also to allow the development of regional details during model integration. The SNT can improve the model's performance in capturing individual weather events and regional characteristics as well as in simulating the mean features of the large-scale driving forces. The implementation of the SNT can successfully decrease the uncertainty of the domain choice in the long-term simulation of RCM (Miguez-Macho et al. 2004) and reduce the systematic errors of the simulated precipitation in terms of the spatial pattern (Lee et al. 2004; Cha and Lee 2009; Cha et al. 2016a, b). Lee et al. (2004, 2013) successfully showed that the simulations of extreme summer rainfall in East Asia and the 70-year regional climate over Asia resulted from the reasonable monsoon circulations owing to the effect of the SNT. In addition, Cha and Lee (2009) indicated that the SNT could considerably improve the simulation of monsoon precipitation over the subtropical western North Pacific (WNP), because it significantly reduced the systematic error in atmospheric circulation induced by unreasonable physical processes; the control experiment without the SNT overestimated precipitation over the subtropical WNP (Fig. 1b) due to exaggerated low-level westerly from the Indian ocean to the WNP and the shrunken subtropical high (Fig. 1e). On the contrary, the experiment with the SNT prominently improved simulated monsoon precipitation (Fig. 1c) and synoptic conditions (Fig. 1f).

\section{c) Improvement of physical parameterization}

The imperfectness of physical parameterizations such as radiative transfer package, planetary boundary layer (PBL) scheme, cumulus convective parameterization scheme (CPS), and explicit moisture scheme (EMS) can be associated with the systematic errors of RCMs. Many researchers have studied the uncertainties of CPS and EMS in regional climate modeling (e.g., Giorgi and Shields 1999; Gochis et al. 2002; Lee et al. 2005). In addition to EMS and CPS, the PBL scheme can result in significant errors as it plays an essential role in determining the exchanges of momentum, moisture, and energy among atmosphere, land, and ocean in the long-term simulation of RCM.

The SNURCM has been applied in several research programs on regional climate simulation of the East Asia summer monsoon (EASM). However, an overestimation of precipitation over the ocean was also exhibited in most researches with the SNURCM, which is a prominent systematic error. This error tended to significantly increase when the CPS including the downdraft processes were used (Lee et al. 2005). Therefore, the Yonsei University (YSU) boundary layer scheme (Hong et al. 2006), which is an improved PBL scheme, was implemented into the SNURCM to reduce the systematic error of overestimation of precipitation over the ocean. Cha et al. (2008) examined the effect of PBL processes on the simulation of EASM through the RCM experiments with the YSU and MRF schemes for the extreme floods over East Asia during the summer of 1998. They showed that the MRF scheme overestimated precipitation over the subtropical WNP because it exaggerated PBL mixing, which led to an unrealistic feedback process between latent heat flux at the sea surface and precipitation (Fig. 2b). In contrast, the YSU scheme with relatively reduced PBL mixing improved the seasonal mean precipitation and associated monsoon circulations over the subtropical WNP (Fig. 2c).

\section{d) Implementation of coupled air-sea interaction}

Air-sea interaction over the WNP tends to be relatively strong owing to high sea surface temperature (SST). However, the RCM simulations forced by observed or by GCM SST do not include reasonable air-sea interaction. That is, this type of RCM has the reactions of atmosphere to SST change but no interactions between the atmosphere and SST. For example, Ren and Qian (2005) indicated that a regional coupled climate model was useful in simulating the EASM despite the presence of a cold drift in SST in their model. Therefore, the development of a regional earth system model (the coupled SNURCM), in which atmosphere, land, and ocean models were combined, was needed. A slab ocean model (SOM) was coupled with the SNURCM to calculate SST and ocean temperature. The slab ocean model coupled with the SNURCM was modified from the lake model (Zeng et al. 2002) that utilizes the concepts from the lake models developed by Bonan (1996), Henderson-Sellers (1985, 1986), and Hostetler and Bartlein (1990), and the coupled lake-atmosphere model developed by Hostetler et al. $(1993,1994)$.

Using the SNURCM coupled with SOM, Cha et al. (2016a) conducted three experiments to investigate the effects of coupled air-sea interaction; the CTL experiment without the coupled air-sea interaction and the spectral nudging, the SOM experiment with a slab ocean model, and the SOM_ISN experiment with a slab ocean model as well as the spectral nudging. They showed that the CTL experiment had considerable systematic errors of precipitation over the subtropical WNP, subtropical high, and low-level circulations. The errors were associated with an erroneous physical process induced by the effect of one-way (uncoupled) air-sea interaction. In contrast, the SOM experiment 

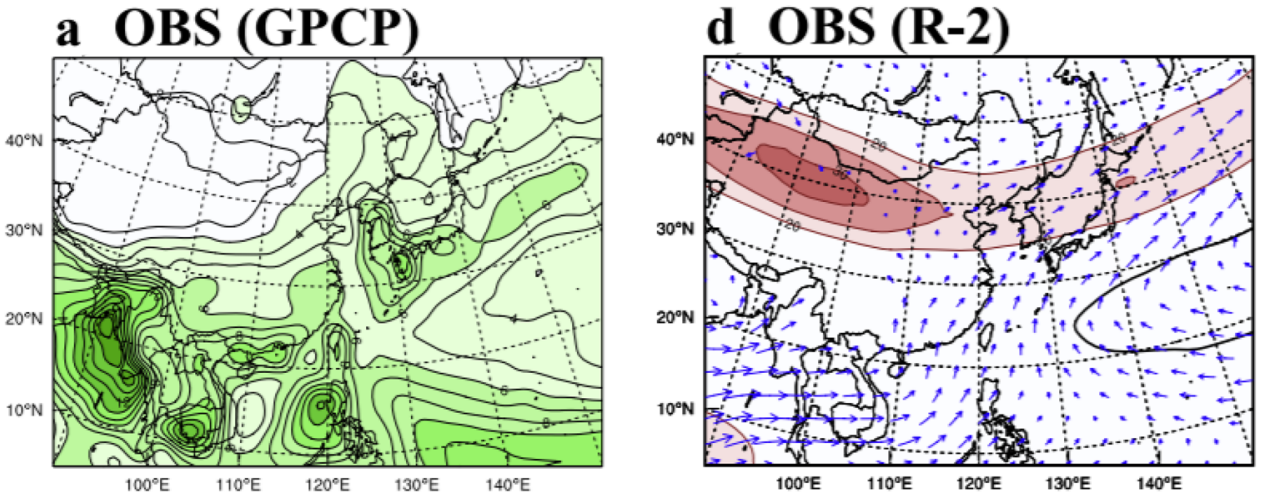

\section{b CTL}

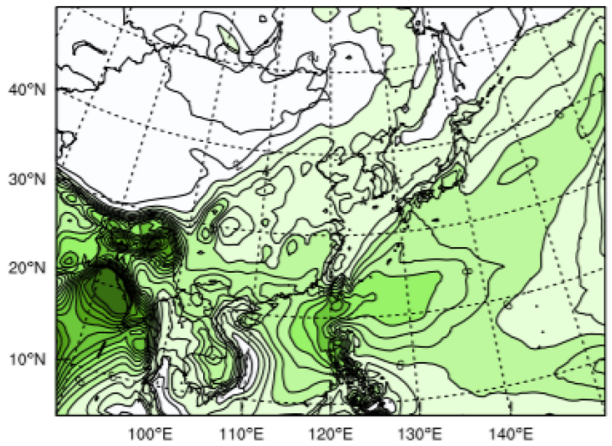

c SP

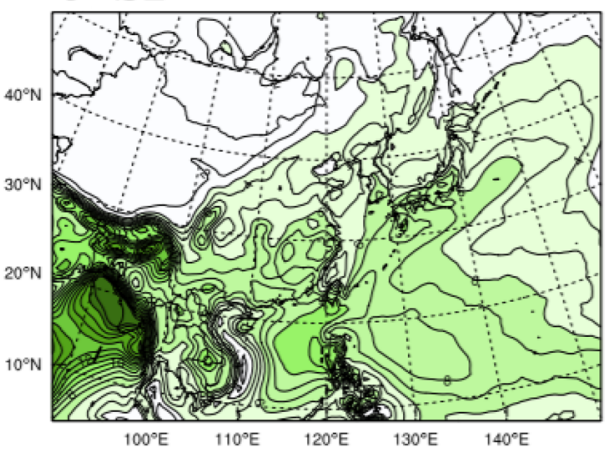

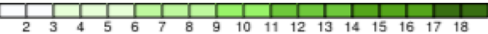

\section{e CTL}
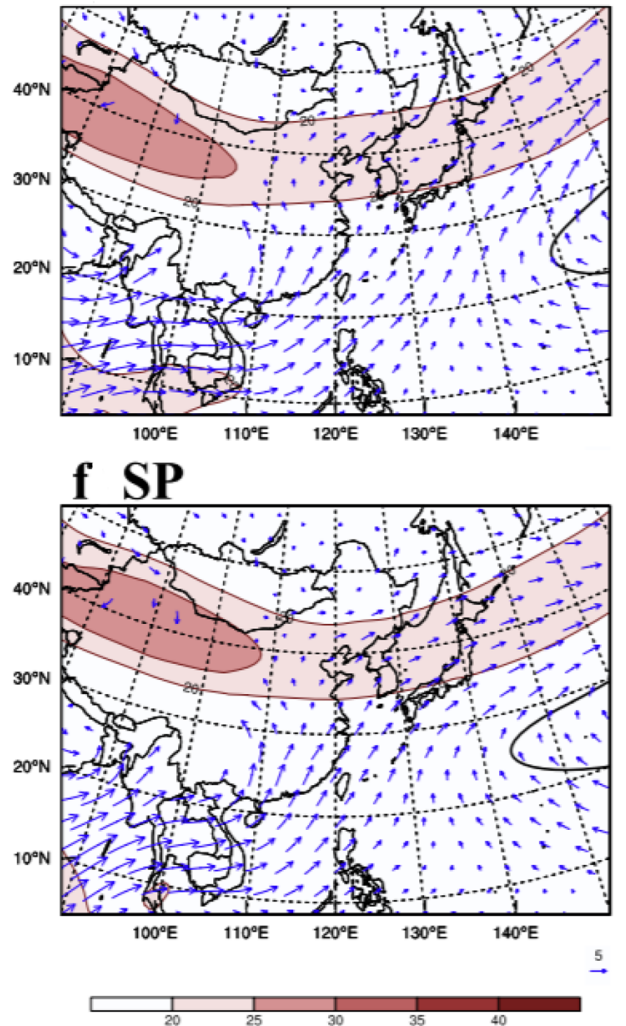

Fig. 1 a-c 28-year (1979-2006) climatology of seasonal mean precipitation $\left(\mathrm{mm} \mathrm{day}^{-1}\right)$ and $\mathbf{d}$-f $\mathbf{f} 28$-year climatology of seasonal mean $850 \mathrm{hPa}$ wind vector, $200 \mathrm{hPa}$ wind speed ( $\mathrm{m} \mathrm{s}^{-1}$, contour and shading), and 5880 geopotential height contours (solid lines). Upper, mid, and bottom panels indicate observation, control experiment (no nudging), and spectral nudging experiments, respectively (adapted from Cha and Lee (2009))

reduced the unrealistic process because the simulated SST decreased with increasing ocean mixing from the intensified low-level wind. Thus, the coupled air-sea interaction by the implementation of the SOM could improve the simulations of seasonal mean precipitation and synoptic fields. In particular, the coupled air-sea interaction significantly improved the interannual variability of the EASM. In Fig. 3 showing the PC time series of the first eigenvector from the empirical orthogonal function (EOF) analysis of seasonal mean precipitation, the temporal correlation coefficient between observation and the SOM experiment is prominently higher than that between observation and the CTL experiment indicating significant improvement of EASM variability by coupled air-sea interaction. This implies that the development of the coupled RCMs that adjust the simulated SST to atmospheric conditions is 


\section{a OBS}

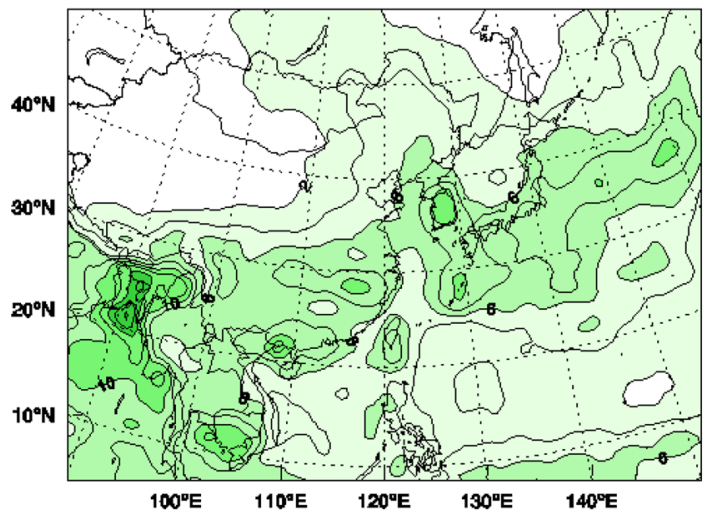

b MRF

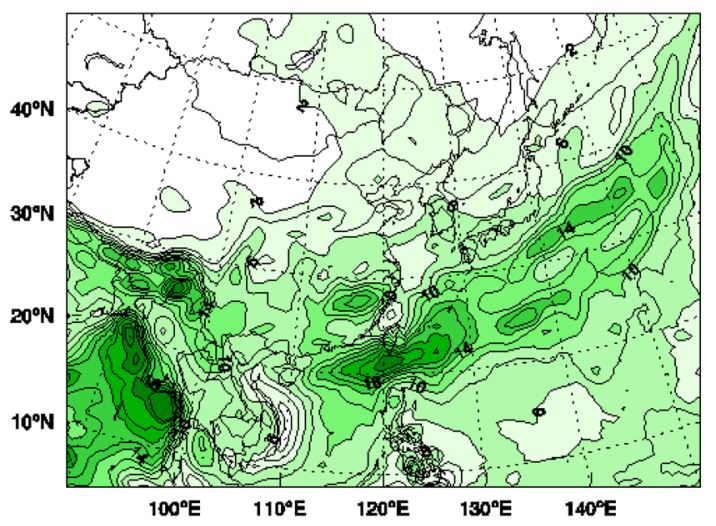

c YSU

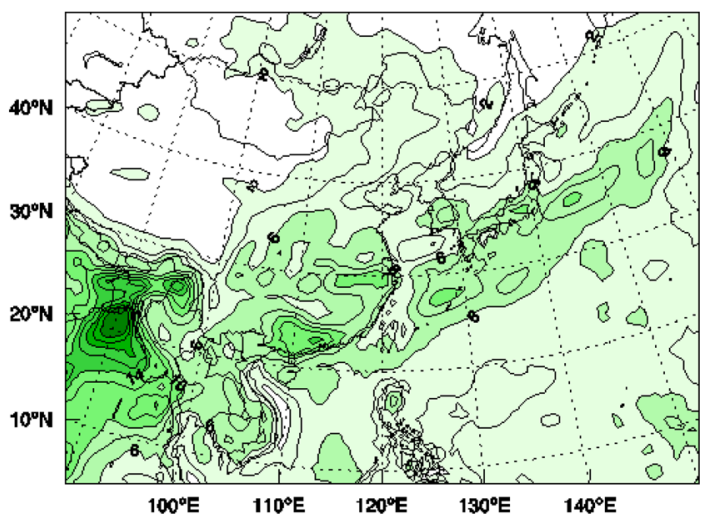

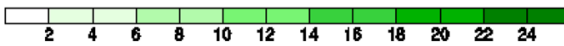

Fig. 2 Seasonal mean precipitation over East Asia during the summer of 1998 (JJA) in a GPCP observation and experiments with b MRF scheme and c YSU scheme (adapted from Cha et al. (2008))

required for advanced simulation of the Asian climate using RCMs.

\section{Application and international cooperation}

The SNURCM has been applied in numerous research programs such as future climate projection, extreme climate reproduction, seasonal forecasting, and international regional climate model comparison. In this section, we introduce various application studies and two international cooperation projects that used the SNURCM.

\section{a) Applications}

Under the changing climate, property damage and casualty associated with high-impact weather and climate events have been significantly increasing with the growth of human activity (Solomon et al. 2007). For the climate change adaptation, more accurate and detailed projections of future climate are required. Therefore, RCMs have been generally used to generate fine-scale future scenarios of climate change (Christensen et al. 2007; Van der Linden and Mitchell 2009; Suh et al. 2012).

The SNURCM was also used to produce fine-scale climate change scenarios via downscaling of GCM outputs as fruitful references for adaptation planning in Korea. Lee et al. (2013) conducted 70-year (1980-2049) regional climate simulations with the multi-nested SNURCM based on the Special Reports on Emission Scenarios (SRES) B1 scenario and analyzed future 


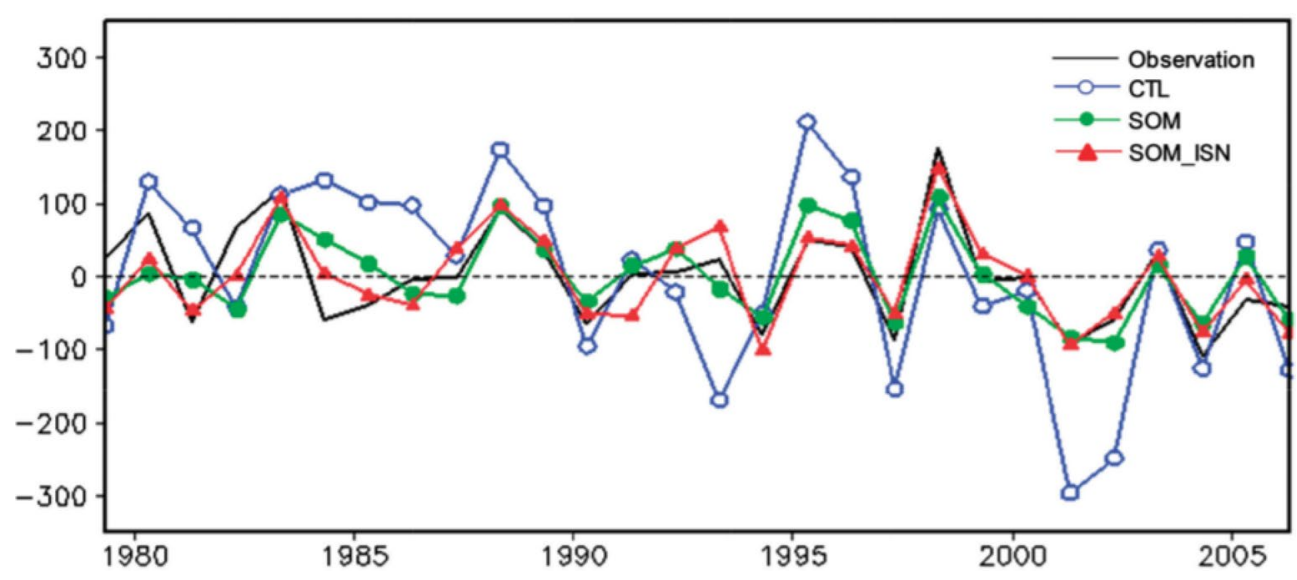

Fig. 3 Corresponding PC time series of the first model eigenvector from the empirical orthogonal function (EOF) analysis of seasonal mean precipitation related to the interannual variability of the EASM. The temporal correlation coefficient between observation and the CTL experiment is 0.57 , while that between observation and the SOM experiment is 0.71 (adapted from Cha et al. $(2016 a, b)$ )

regional climate changes over the Korean Peninsula and East Asia focusing on the impact of global warming on extreme climate events. They showed that warming surface temperature resulted from increasing net longwave radiations at the surface and that decreasing precipitation could be induced by the northward shifted rain band of monsoon and the expanded subtropical high. In addition, the study indicated that the
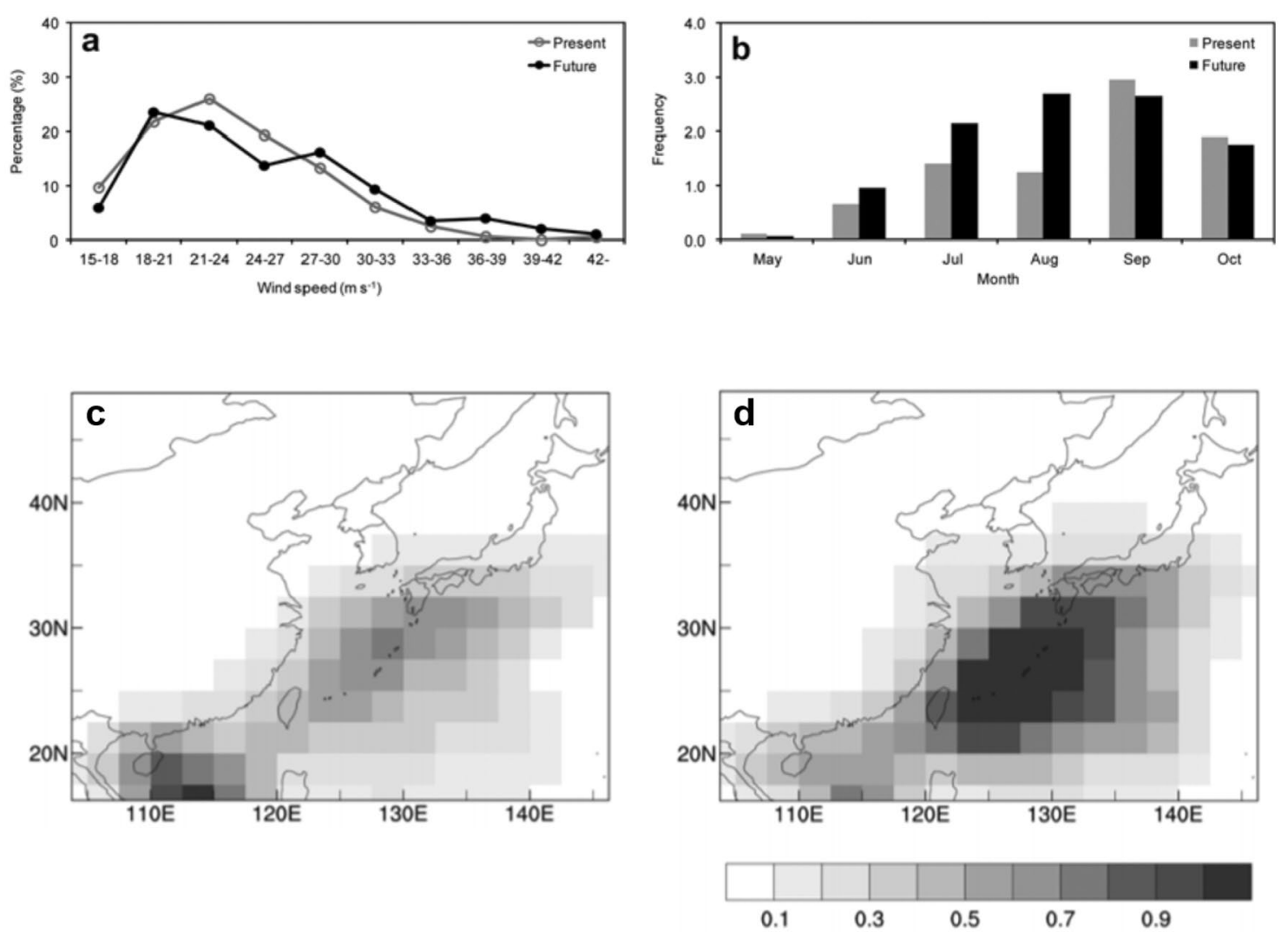

Fig. 4 a Changes in maximum wind speed at $850 \mathrm{hPa}$ around the TC core, $\mathbf{b}$ monthly frequency of TC genesis (number/20 years), and track density of TC for c present 20-year (1980-1999) and (d) future 20-year (2030-2049) (adapted from Lee et al. (2013)) 
intensity of tropical cyclones (TCs) over the WNP could be enhanced (Fig. 4a), and TC activity in the midlatitudes might increase in the future (Fig. 4c, d).

In Cha et al. (2016b), the regional climate around Korea was dynamically downscaled with the fine-resolution $(12.5 \mathrm{~km})$ SNURCM forced by the Representative Concentration Pathways (RCP) scenarios of the Hadley Global Environment Model 2-atmosphere and ocean (HadGEM2-AO) model and future precipitation change was especially analyzed. All experiments using four RCP radiative forcings (i.e., RCP 2.6, RCP 4.5, RCP 6.0, and RCP 8.5) projected increasing future summer precipitation (Fig. 5). However, there were some differences in changing rates of precipitation depending on RCP scenarios, which indicated the uncertainty of future precipitation change. The experiments showed that the uncertainty could be attributed to the simulation of monsoon circulation, which determined the moisture advection to the Korean Peninsula. In addition, Kim et al. (2018) indicated that extreme precipitation intensities in the future climate significantly increased because of enhanced convective instability.

In addition to future projection studies, the SNURCM was employed to reproduce extreme climate events in Asia and understand the related physical mechanisms. Lee et al. (2004) simulated the severe rainfall case over

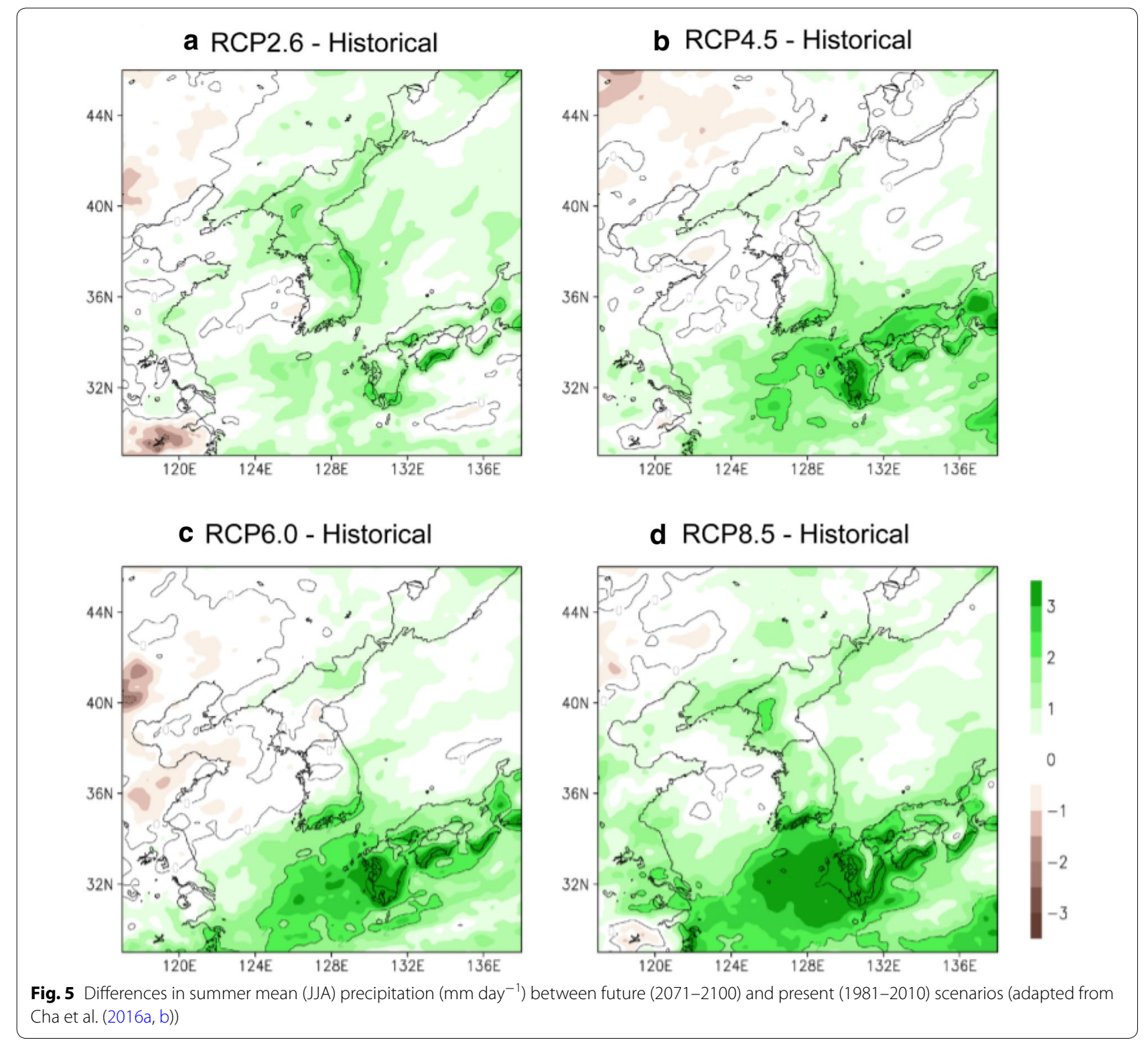


East Asia during the summer of 1998 using the SNURCM with multiple nesting domains and showed that the model had the ability to capture the abnormal monsoon fronts in 1998 that induced extreme flooding, and the higher model resolution $(20 \mathrm{~km})$ could lead to the improved simulation of heavy precipitation compared with the lower resolution $(60 \mathrm{~km})$. Lee et al. (2005) indicated that the proper selection of the convection scheme was required for better simulation of the extreme precipitation event. In addition, Choi et al. (2008) simulated an 18-day consecutive heavy precipitation in Korea during August 1998 using the SNURCM and investigated the potential predictability and the impacts of a time-lagged ensemble method and increasing model resolution. They found that the intensity and amount of heavy rainfall and its diurnal variation were more reasonably simulated by the combined impacts of detailed topography and increased horizontal resolution (Fig. 6). Jin et al. (2016) showed that the SNURCM had the ability to reproduce TC activities over the WNP, which resulted in significant damage in Asian countries.

The SNURCM was also used to understand regional climate processes in Asia. Cha et al. (2011a) examined the impact of the local SST anomaly on the extreme EASM through sensitivity tests on the local SST and found that the SST anomaly over the WNP could reduce the precipitation anomaly by modulating large-scale circulations and surface latent heat flux (e.g., the local Walker and Hadley circulations). They showed that the experiment using climatological SST (CSST) has larger interannual variability (i.e., standard deviation) compared with that using normal SST (CTL), indicating that the local SST anomaly over the WNP can play a role in reducing the extreme EASM (Fig. 7d).

\section{b) International cooperation}

The SNURCM has been used in international cooperative projects to generate future climate projections using multi-RCMs. With the support of the Asia-Pacific Network for Global Change Research (APN), the Regional Climate Model Intercomparison Project (RMIP) for Asia was established in the late 1990s to examine the performance of multi-RCMs over Asia (Fu et al. 2005). The RMIP had three simulation phases: the first phase during March 1997-August 1998, which included extreme monsoon events of 2 years and a full annual cycle; the second phase during January 1989-December 1998, which investigated simulated climatology; and the third phase for a 30-year (2040-2070) future projection of regional climate change, involving the nesting from a global model (Li et al. 2016; Tang et al. 2016; Wu et al. 2016). The SNURCM contributed to all the phases of the RMIP.

The SNURCM also joined the research program of the Coordinated Regional Climate Downscaling Experiment (CORDEX)_East Asia (Giorgi et al. 2009), which was initiated as a successor of the RMIP with the additional support of the Korea Meteorological Administration (KMA). The CORDEX-East Asia program has two phases: phase I is for the dynamical downscaling of the Coupled Model Intercomparison Project Phase 5 (CMIP5) output using a

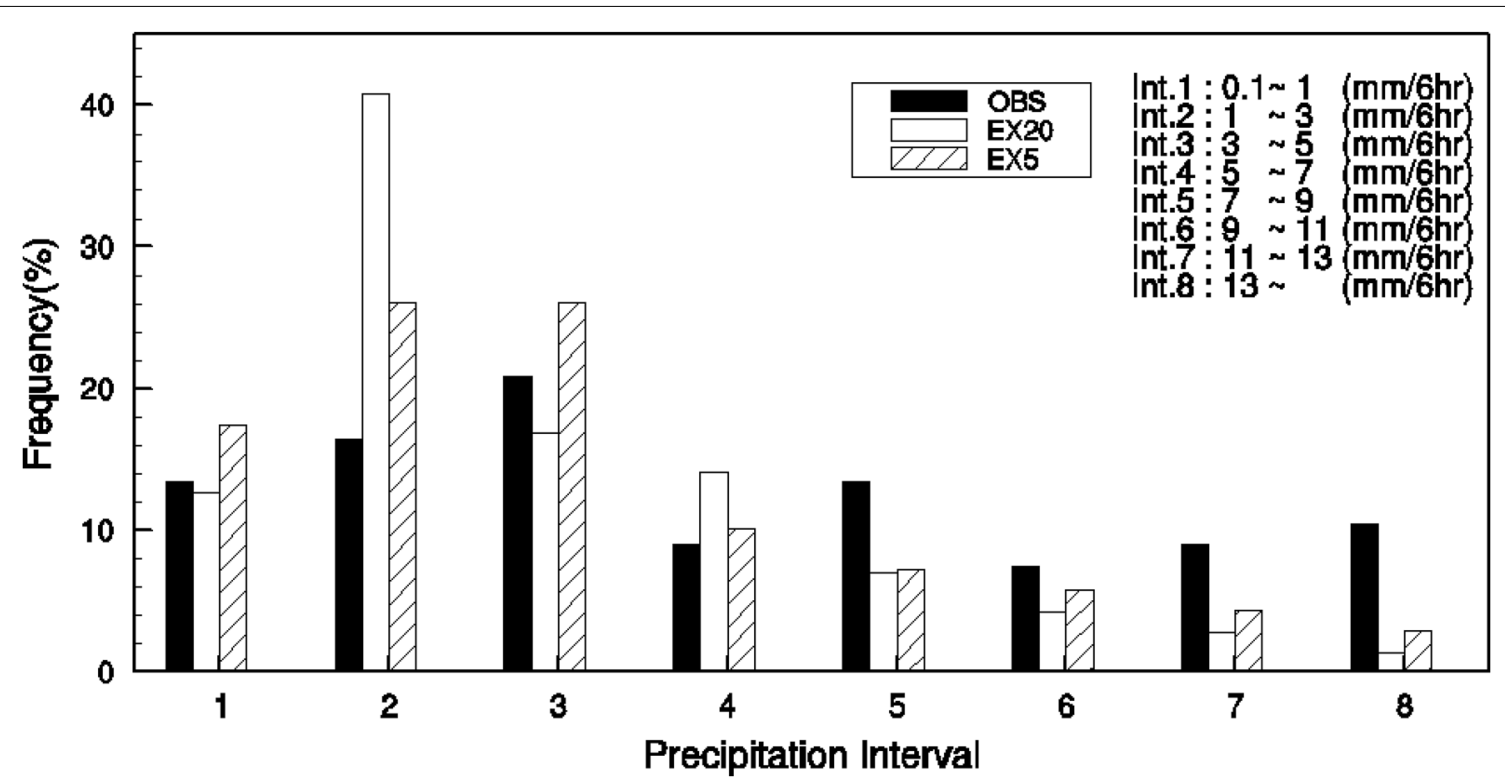

Fig. 6 Station-averaged 6-h accumulated precipitation intensity over the Korean Peninsula ( $\left.125-130^{\circ} \mathrm{E}, 34-39^{\circ} \mathrm{N}\right)$ for the 18 days in observation and experiments with 20-km (EX20) and 5-km (EX5) horizontal resolutions. The frequency of intensity within a given interval is represented as the percentage of the total number of rain occurrences (adapted from Choi et al. (2008)) 

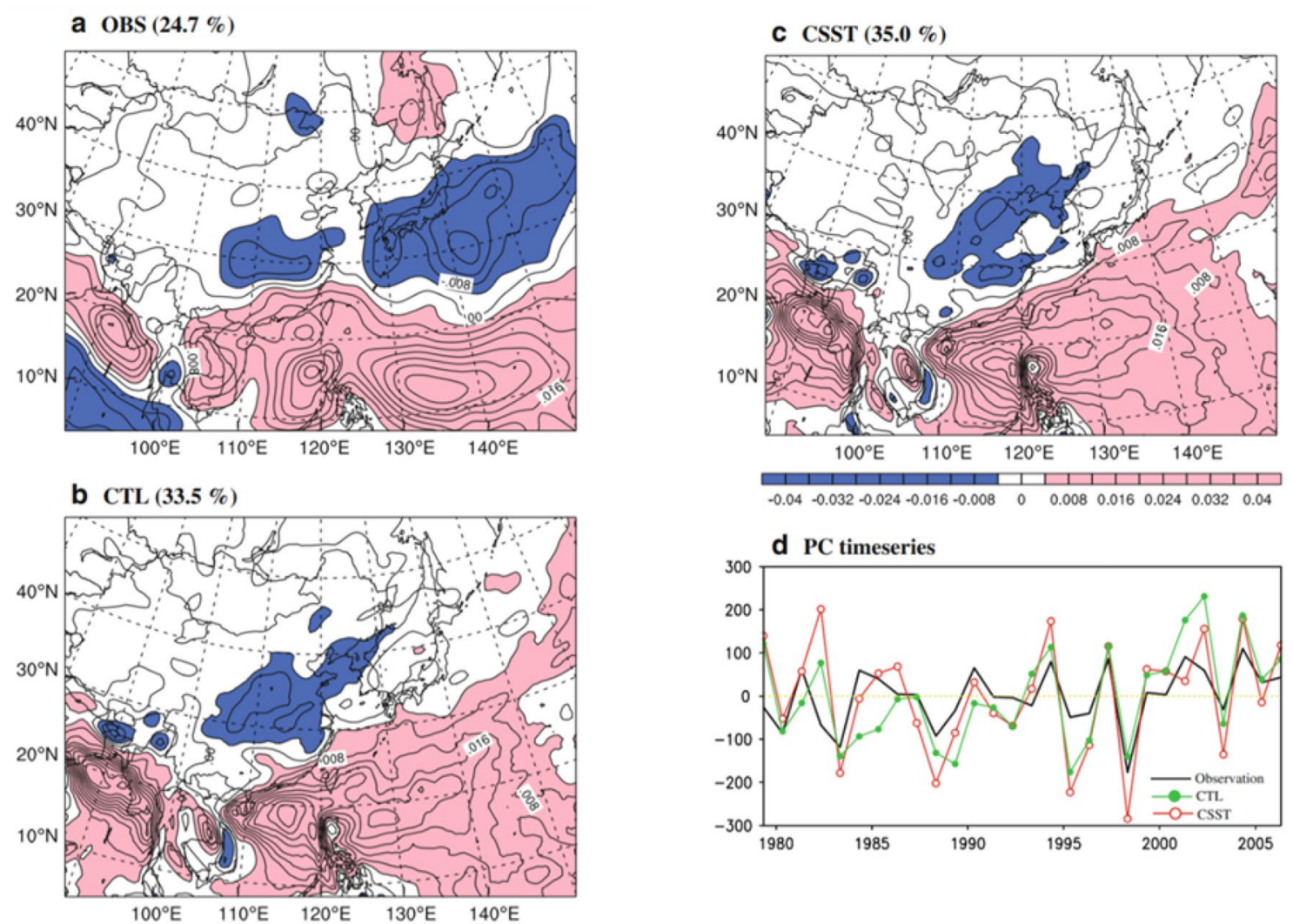

Fig. 7 a-c First mode eigenvectors and $\mathbf{d}$ corresponding PC time series from the EOF analysis of seasonal mean (JJA) precipitation (adapted from Cha et al. (2011a))

coarser-resolution $(\sim 50 \mathrm{~km}) \mathrm{RCMs}$, and the phase II is for the downscaling of CMIP5/CMIP6 output with a higherresolution $(\sim 25 \mathrm{~km})$ RCMS. There have been many research activities on gathering climate-related information using multi-RCMs in CORDEX-East Asia Phase I. Lee et al. (2014) demonstrated that the increasing temperature over East Asia was distinctly associated with intensified monsoon precipitation. Jin et al. (2016) showed that the RCMs in the CORDEX-East Asia phase I properly captured the climatological spatial distribution and interannual variability of TC activities over the WNP. Lee et al. (2019) showed that the TCs activities in the extra-tropical regions (e.g., Korea and Japan) could increase significantly owing to the changes in the synoptic patterns such as decreased vertical wind shear, expanded subtropical high, and increased SST. Kim et al. (2020b) also projected future changes of precipitation in the CORDEX-East Asia Phase I and showed that both extreme and mean precipitation amounts increased over northern China and Korea under the RCP 4.5 and RCP 8.5 scenarios in the mid-twenty-first-century period (20252049). It is noted that there were robust differences in both regions and RCP scenarios, thus implying the detailed impacts of the regional model (Fig. 8). They also indicated that the increment of future precipitation could be attributed to the low-level increases in water vapor in all seasons, which were caused by intensified monsoon circulation in the mid-latitudes.

\section{Conclusion}

RCM is an important tool that reproduces and projects finescale climate information that cannot be captured by GCMs because of its higher resolution and sophisticated physical processes. To simulate the intrinsic and detailed climate in Asia, we have developed an RCM termed as the SNURCM in the late 1990s and applied it to a number of applicationoriented studies and international cooperation. In this study, we reviewed the developmental processes of the SNURCM and introduced its application researches.

Most of the RCMs have reproduced realistic regional climatic conditions by decreasing systematic errors. In the regional climate simulation over Asia, errors can be generated by natural characteristics such as complex land-surface conditions and topography, warm ocean conditions, and strong seasonal monsoon circulation and convection. To reduce the errors, numerous methods and techniques have been applied to the SNURCM. For long-term 

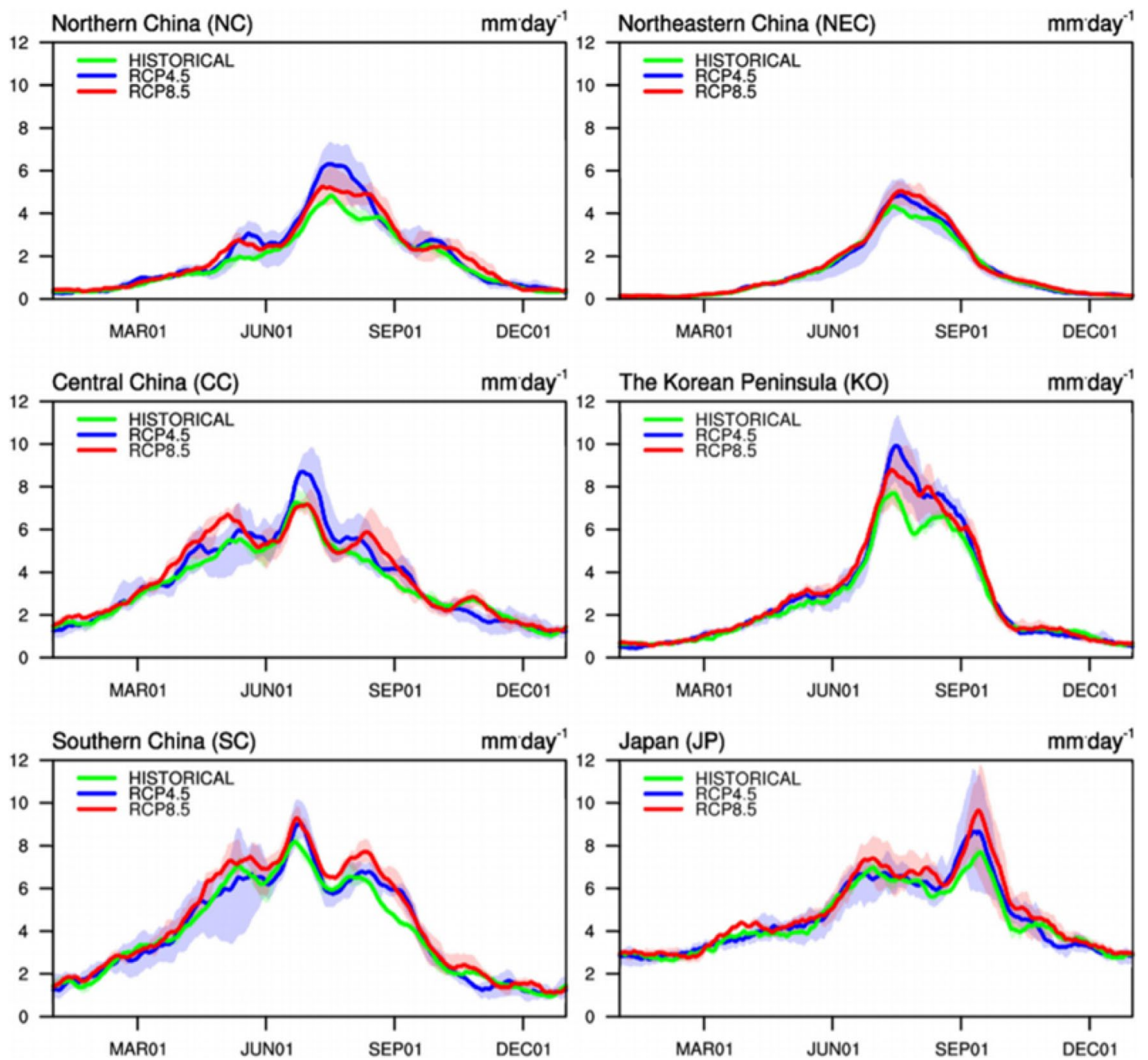

Fig. 8 The annual cycle of the area-averaged precipitation $\left(\mathrm{mm} \mathrm{day}^{-1}\right)$ over the six sub-regions of the multi-model ensemble in historical (green), RCP 4.5 (blue), and RCP 8.5 (red) experiments. Blue and red areas represent model spread between the RCMs in RCP 4.5 and RCP 8.5 experiments, respectively (adapted from Kim et al. (2020b))

simulations without climate drift, the spectral nudging technique as well as the traditional relaxation method was employed for the boundary conditions. To represent reasonable interactions between earth systems, a simple ocean model and an advanced land-surface model (CLM) were implemented into the SNURCM. Physical schemes for precipitation and vertical diffusion that were developed for short-term numerical weather prediction models were optimized or improved for long-term simulation. The RCM has been applied for projecting future climate, reproduction of extreme climate, and seasonal forecasting. Furthermore, the model has served as a part of the multimodel comparison program and an ensemble of international research programs such as RMIP and CORDEX.
Although the SNURCM was based on the old MM5, it has been one of the representative RCMs for East Asian climate involved in international researches such as the CORDEX program. However, there are also the limitations of the SNURCM based on the MM5 such as parallelizing and old physical parameterization schemes. Therefore, we have also developed the SNURCM based on the weather research and forecasting (WRF) model (Cha et al. 2011b; Jin et al. 2013; Yoon et al. 2018; Kim et al. 2019).

We are convinced that the development processes of the SNURCM introduced in this study can be a good reference for regional climate modeling researches to develop and improve RCMs for East Asian climate, and the researches using the SNURCM can provide helpful information to 
application studies in other fields. For future studies of regional climate for Asia, it is suggested that RCMs include physical interactions between atmosphere, land, and ocean as well as the impacts of aerosol and dynamic vegetation changes, which can contribute to the more realistic simulation of complex Asian climate. Furthermore, RCMs with a very high model resolution of less than $5 \mathrm{~km}$, which can add more value to the process of simulation of high-impact weather and climate events (e.g., TCs and heavy rainfall), should be studied because the high-resolution GCMs have been more widely used for recent climate researches. Therefore, we have plans to develop a regional earth system model and a convection-permitting RCM based on the SNURCM. Using the SNURCM, the effect of twoway interaction (i.e., downscaling and upscaling) between RCMs and GCMs will also be investigated to overcome the limitation of boundary conditions.

\section{Acknowledgements}

This study summarized the special lecture of Prof. Dong-Kyou Lee for the 2017 Axford medal award, which reviewed the developmental processes of the SNURCM and its applications. We appreciate the strong support of NCAR MMM (National Center for Atmospheric Research, Mesoscale and Microscale Meteorology Division) for mutual research collaboration with SNU. We thank the partnership of all principal investigators and scientists involved in the international cooperative program. Many thanks go to all students and scientists of the Numerical Weather Prediction Lab (NWPL) of Seoul National University for their contributions to the development of SNURCM since the 1990s.

\section{Authors' contributions}

Dong-Kyou Lee organized and wrote the manuscript and Dong-Hyun Cha revised it. Both authors read and approved the final manuscript.

\section{Funding}

This work was funded by the Korea Meteorological Administration Research and Development Program under Grant KMI (KMI2018-01211).

\section{Availability of data and materials}

Not applicable.

\section{Competing interests}

The authors declare that they have no competing interests.

\section{Author details}

${ }^{1}$ School of Earth and Environmental Sciences, Seoul National University, Seoul, Republic of Korea. ${ }^{2}$ School of Urban and Environmental Engineering, Ulsan National Institute of Science and Technology (UNIST), 50 UNIST-gil, Ulju-gun, Ulsan 689-798, Republic of Korea.

Received: 17 March 2020 Accepted: 6 August 2020

Published online: 14 August 2020

\section{References}

Ahn YI, Lee DK (2002) Impact of bogus tropical cyclones on summertime circulation in regional climate simulation. J Geophys Res. https://doi. org/10.1029/2001JD000416

Bonan GB (1996) A land surface model (LSM version 1.0) for ecological, hydrological, and atmospheric studies: Technical description and User's guide, NCAR/TN-417 + STR, NCAR Tech. Note. pp 150

Bonan GB, Oleson KW, Vertenstein M, Levis S, Zeng X, Dai Y, Dickinson RE, Yang Z-L (2002) The land surface climatology of the community land mode coupled to the NCAR community climate model. J Clim 15:3123-3149
Bosilovich MG, Sun W-Y (1999) Numerical simulation of the 1993 midwestern flood: land-atmosphere interactions. J Clim 12:1490-1505

Cha D-H, Lee D-K (2009) Reduction of systematic errors in regional climate simulations of the summer monsoon over East Asia and the western North Pacific by applying the spectral nudging technique. J Geophys Res 114:D14108. https://doi.org/10.1029/2008JD011176

Cha D-H, Lee D-K, Hong S-Y (2008) Impact of boundary layer processes on seasonal simulation of the East Asian summer monsoon using a regional climate model. Meteorol Atmos Phys 100:53-72

Cha D-H, Jin C-S, Lee D-K (2011a) Impact of local SST anomaly over the western North Pacific on extreme East Asian summer monsoon. Clim Dyn 37:1691-1705. https://doi.org/10.1007/s00382-010-0983-z

Cha D-H, Jin C-S, Lee D-K, Kuo Y-H (201 1b) Impact of intermittent spectral nudging on regional climate simulation using Weather Research and Forecasting model. J Geophys Res 116:D10103. https://doi. org/10.1029/2010JD015069

Cha D-H, Jin C-S, Moon J, Lee D-K (2016a) Improvement of regional climate simulation of East Asian summer monsoon by coupled air-sea interaction and large-scale nudging. Int J Climatol 36:334-345

Cha D-H, Lee D-K, Jin C-S, Kim G, Choi Y-H, Suh M-S, Ahn J-B, Hong S-Y, Min S-K, Park S-C, Kang H-S (2016b) Future changes in summer precipitation in regional climate simulations over the Korean Peninsula forced by multiRCP scenarios of HadGEM2-AO. Asia-Pac J Atmos Sci 52:139-149

Choi S-J, Cha D-H, Lee D-K (2008) Simulation of the 18-day summer heavy rainfall over East Asia using a regional climate model. J Geophys Res 113:D12101. https://doi.org/10.1029/2007JD009213

Christensen JH, Carter TR, Rummukainen M, Amanatidis G (2007) Evaluating the performance and utility of regional climate models: the PRUDENCE project. Clim Change 81:1-6. https://doi.org/10.1007/s10584-006-9211-6

Dai A, Giorgi F, Trenberth KE (1999) Observed and model-simulated diurnal cycles of precipitation over the contiguous United States. J Geophys Res 104:6377-6402

Dickinson RE, Errico RM, Giorgi F, Bates GT (1989) A regional climate model for the western United States. Clim Change 15:383-422

Davis HC, Turner RE (1977) Updating prediction models by dynamical relaxation: an examination of the technique. J Appl Meteorol 17:998-1013

Fu C, Wang S, Xiong Z, Gutowski WJ, Lee DK, McGregor JL, Sato Y, Kato H, Kim JW, Suh MS (2005) Regional climate model intercomparison project for Asia. Bull Am Meteorol Soc 86:257-266

Giorgi F, Mearns LO (1999) Introduction to special section: regional climate modeling revisited. J Geophys Res 104:6335-6352

Giorgi F, Shields C (1999) Tests of precipitation parameterizations available in the latest version of the NCAR regional climate model (RegCM) over the continental U.S. J Geophys Res 104:6353-6376

Giorgi F, Shields C, Bates GT (1994) Regional climate change scenarios over the United States produced with a nested regional climate model. J Clim 7:375-399

Giorgi FC, Jones GR, Asrar (2009) Addressing climate information needs at the regional level: the CORDEX framework. World Meteorol Org WMO Bull 58:175

Gochis DJ, Shuttleworth WJ, Yang ZL (2002) Sensitivity of the modeled North American monsoon regional climate to convective parameterization. Mon Wea Rev 130:1282-1298

Grell GA, Dudhia J, Stauffer DR (1994) A description of the fifth-generation Penn State/NCAR mesoscale model (MM5). NCAR/TN-398 + STR, NCAR Technical Note, NCAR, Boulder, CO. pp 122

Giorgi F (1990) Simulation of regional climate using a limited area model nested in a general circulation model. J Clim 2:941-963

Giorgi F (2006) Regional climate modeling: Status and perspectives. In: Journal de Physique IV (proceedings). EDP sciences, p. 101-118

Henderson-Sellers B (1985) New formulation of eddy diffusion thermocline models. Appl Math Model 9:441-446

Henderson-Sellers B (1986) Calculating the surface energy balance for lake and reservoir modeling, a review. Rev Geophys 24:625-649

Hong S-Y, Noh Y-G, Dudhia J (2006) A new vertical diffusion package with an explicit treatment of entrainment processes. Mon Wea Rev 134:2318-2341

Hostetler SW, Bartlein PJ (1990) Simulation of lake evaporation with application to modeling lake level variations of Harney-Malheur Lake, Oregon. Wat Resour Res 26:2603-2612

Hostetler SW, Bates GT, Giorgi F (1993) Interactive coupling of a lake thermal model with a regional climate model. J Geophys Res 98:5045-5057 
Hostetler SW, Giorgi F, Bates GT, Bartlein PJ (1994) Lake-atmosphere feedbacks associated with paleolakes Bonneville and Lahontan. Science 263:665-668

Jeon D-J, Ligaray M, Kim M, Kim G, Lee G, Pachepsky YA, Cha D-H, Cho KH (2019) Evaluating the influence of climate change on the fate and trans port of fecal coliform bacteria using the modified SWAT model. Sci Total Envrion 658:753-762

Jin C-S, Ho C-H, Kim J-H, Lee D-K, Cha D-H, Yeh S-W (2013) Critical role of northern off-equatorial sea surface temperature forcing associated with central Pacific El Niño in more frequent tropical cyclone movements toward East Asia. J Clim 26:2534-2545

Jin C-S, Cha D-H, Lee D-K, Suh M-S, Hong S-Y, Kang H-S, Ho C-H (2016) Evaluation of climatological tropical cyclone activity over the western North Pacific in the CORDEX-East Asia multi-RCM simulations. Clim Dyn 47:765-778

Kang H-S, Cha D-H, Lee D-K (2005) Evaluation of the MM5/LSM coupled model for East Asian summer monsoon simulations. J Geophys Res 110:D10105. https://doi.org/10.1029/2004JD0005266

Kim J, Miller NL, Farrara JD, Hong S-Y (2000) A seasonal precipitation and stream flow hindcast and prediction study in the Western United States during the 1997/98 winter season using a dynamic downscaling system. J Hydrometeorol 1:311-329

Kim G, Cha D-H, Park C, Lee G, Jin C-S, Lee D-K, Suh M-S, Ahn J-B, Min S-K, Hong S-Y, Kang H-S (2018) Future change in extreme precipitation indices over Korea. Int J Climatol 38:e862-e874

Kim J, Cha D-H, Choi Y, Kim J, Son S-W (2019) Impacts of the East Asian winter monsoon and local sea surface temperature on heavy snowfall over the Yeongdong region. J Clim 32:6783-6802

Kim G, Cha DH, Lee G, Park C, Jin CS, Lee DK, Suh MS, Ahn JB, Min SK, kim J (2020a) Projection of future precipitation change over South Korea by regional climate models and bias correction methods. Theor Appl Climatol. https://doi.org/10.1007/s00704-020-03282-5

Kim G, Cha D-H, Park C, Jin C-S, Lee D-K, Suh M-S, Oh S-G, Hong S-Y, Ahn J-B, Min S-K, Kang H-S (2020b) Evaluation and projection of regional climate over East Asia in CORDEX-East Asia Phase I experiment. Asian Pac J Atmos Sci. https://doi.org/10.1007/s13143-020-00180-8

Kim J-E, Hong S-Y (2007) Impact of soil moisture anomalies on summer rainfall over East Asia: A regional climate model study. J Clim 20:5732-5743

Lee D-K, Suh M-S (2000) Ten-year Asian summer monsoon simulation using a regional climate model (RegCM2). J Geophys Res 105:29565-29577

Lee D-K, Cha D-H, Kang H-S (2004) Regional climate simulation of the 1998 summer flood over East Asia. J Meteorol Soc Jpn 82:1735-1753

Lee D-K, Cha D-H, Choi S-J (2005) A sensitivity study of regional climate simulation to convective parameterization schemes for 1998 East Asian summer monsoon. Terr Atmos Ocea Sci 16:989-1015

Lee D-K, Cha D-H, Jin C-S, Choi S-J (2013) A regional climate change simulation over East Asia. Asia Pac J Atmos Sci 49:655-664

Lee JW, Hong S-Y, Chang E-C, Suh M-S, Kang H-S (2014) Assessment of future climate change over East Asia due to the RCP scenarios downscaled by GRIMs-RMP. Clim Dyn 42:733-747. https://doi.org/10.1007/s0038 2-013-1841-6

Lee H, Jin C-S, Cha D-H, Lee M, Lee D-K, Suh M-S, Hong S-Y, Kang H-S (2019) Future change in climatological tropical cyclone activity over the 2 western North Pacific in the CORDEX-East Asia Multi-RCM simulations. J Clim 32:5053-5067

Leung LR, Ghan SJ (1998) Parameterizing subgrid orographic precipitation and surface cover in climate models. Mon Wea Rev 126:3271-3291

Leung LR, Ghan SJ (1999) Pacific Northwest climate sensitivity simulated by a regional climate model driven by a GCM. Part I: control simulations. J Clim 12:2010-2030

Leung LR, Mearns LO, Giorgi F, Wilby RL (2003) Regional climate research. Bull Am Meteorol Soc 84:89-95

Li Q, Wang S, Lee DK, Tang J, Niu X, Hui P, Gutowski WJ, Dairaku K, MxGregor JL, Katzfey J, Gao X, Wu J, Hong S-Y, Wang Y, Sasaki H (2016) Building Asian climate change scenario by multi-regional climate models ensemble. Part II: mean precipitation. Int J Climatol 36:4253-4264

Marbaix P, Gallée H, Brasseur O, van Ypersele J (2003) Lateral boundary conditions in regional climate models: a detailed study of the relaxation procedure. Mon Wea Rev 131:461-479

Mezghani A, Dobler A, Haugen JE, Benestad RE, Parding KM, Piniewski M, Kardel I, Kundzewicz ZW (2017) CHASE-PL climate projection dataset over
Poland-bias adjustment of EURO-CORDEX simulations. Earth Syst Sci Data 9:905-925. https://doi.org/10.5194/essd-9-905-2017

Miguez-Macho G, Stenchikov GL, Robock A (2004) Regional climate simulation over north America: interaction of local processes with improved largescale flow. J Clim 18:1227-1246

Prudhomme C, Dadson S, Morris D, Williamson J, Goodsell G, Crooks S, Boelee L, Davies H, Buys G, Lafon T, Watts G (2012) Future flows climate: an ensemble of 1-km climate change projections for hydrological application in Great Britain. Earth Syst Sci Data 4:143-148. https://doi. org/10.5194/essd-4-143-2012

Ren X, Qian Y (2005) A coupled regional air-sea model, its performances and climate drift in simulation of the east Asian summer monsoon in 1998. Int J Climatol 25:679-692

Schär C, Luthi D, Beyerle U (1999) The soil-precipitation feedback: a process study with a regional climate model. J Clim 12:722-741

Stocker TF, Qin D, Plattner GK, Tignor MM, Allen SK, Boschung J, Nauels A, Xia Y, Bex V, Midgley PM (2014) Climate change 2013: the physical science basis. In: Contribution of working group I to the fifth assessment report of IPCC the intergovernmental panel on climate change. Cambridge University Press

Suh M-S, Oh S-K, Lee D-K, Cha D-H, Choi S-J, Jin C-S, Hong S-Y (2012) Development of new ensemble methods based on the performance skills of regional climate models over South Korea. J Clim 25:7067-7082

Sun L, Semazzi FHM, Giorgi F, Ogallo L (1999) Application of the NCAR regional climate model to eastern Africa 2. Simulations of interannual variability of short rains. J Geophys Res 104:6549-6562

Tang J, Li Q, Wang S, Lee D-K, Hui P, Niu X, Gutowski W, Dairaku K, McGregor J, Katzfey C, Gao X, Wu J, Hong S-Y, Wang Y, Sasaki H (2016) Building Asian climate change scenario by multi-regional climate models ensemble. Part I: surface air temperature. Int J Climatol 36:4241-4252

van der Linden P, Mitchell JF (2009) ENSEMBLES: climate change and its impacts: summary of research and results from the ENSEMBLES project. Met Office Hadley Centre, FitzRoy Road, Exeter EX13 PB, UK, pp 160

Von Storch H, Langerberg H, Feser F (2000) A spectral nudging technique for dynamical downscaling purposes. Mon Wea Rev 128:3664-3673

Wang Y, Sen OL, Wang B (2003) A highly resolved regional climate model (IPRCReg(M) and its simulation of the 1998 severe precipitation event over China. Part I: model description and verification of simulation. J Clim 16:1721-1738

Wang Y, Leung LR, McGREGOR JL, Lee DK, Wang WC, Ding Y, Kimura F (2004) Regional climate modeling: progress, challenges, and prospects. J Meteorol Soc Jpn 82:1599-1628

Wu F-T, Wang S-Y, Fu C-B, Qian Y, Gao Y, Lee D-K, Cha D-H, Tang J-P, Hong S-Y (2016) Evaluation and projection of summer extreme precipitation over East Asia in the Regional Model Inter-comparison Project. Clim Res 69:45-58

Xue YF, Zeng J, Mitchell KE, Janjic ZRE (2001) The impact of land surface processes on simulations of the U.S. hydrological cycle: a case study of the 1993 flood using the SSiB land surface model in the NCEP Eta regional model. Mon Wea Rev 129(12):2833-2860

Yoon D, Cha DH, Lee G, Park C, Lee MI, Min KH (2018) Impacts of synoptic and local factors on heat wave events over southeastern region of Korea in 2015. J Geophys Res 123:12081-12096

Zeng X, Shaikh M, Dai Y, Dickinson RE, Myneni R (2002) Coupling of the common land model to the NCAR community climate model. J Clim 15:1832-1854

Zhang D-L, Zheng W-Z, Xue Y-K (2003a) A numerical study of early summer regional climate and weather over LSA-East. Part I: model implementation and verification. Mon Wea Rev 131:1895-1909

Zhang J, Cha D-H, Lee D-K (2003b) Investigating the role of MODIS leaf area index and vegetation-climate interaction in regional climate simulations over Asia. Terr Atmos Ocea Sci. https://doi.org/10.3319/ TAO.2008.04.03.01(A)

Zhang J, Cha D-H, Lee D-K (2009) Investigating the role of MODIS leaf area index and vegetation-climate interaction inregional climate simulations over Asia. Terr Atmos Ocea Sci https://doi.org/10.3319/ TAO.2008.04.03.01(A)

\section{Publisher's Note}

Springer Nature remains neutral with regard to jurisdictional claims in published maps and institutional affiliations. 